\title{
High renin and prorenin in plasma and pleural exudate of a patient with the ovarian hyperstimulation syndrome ${ }^{1}$
}

\author{
W. van de Vrie ${ }^{a}$, M.G.A. Baggen ${ }^{a, *}$, W. Visser ${ }^{\text {b }}$, F.H.M. Derkx ${ }^{c}$, B. Morrel ${ }^{d}$, \\ R.J.Th. Ouwendijk ${ }^{\text {a }}$ \\ ${ }^{\text {a }}$ Department of Internal Medicine, IKAZIA Hospital, Montessoriweg 1, 3083 AN Rotterdam, Netherlands \\ ${ }^{\mathrm{b}}$ Department of Obstetrics and Gynaecology, Dijkzigt Hospital, Dr. Molewaterplein 40, 3015 GD Rotterdam, Netherlands \\ ${ }^{c}$ Department of Internal Medicine, Dijkzigt Hospital, Dr. Molewaterplein 40, 3015 GD Rotterdam, Netherlands \\ d Department of Obstetrics and Gynaecology, IKAZIA Hospital, Montessoriweg I, 3083 AN Rotterdam, Netherlands
}

Received 6 January 1997; revised 4 June 1997; accepted 5 August 1997

\begin{abstract}
We present the case of a 35-year-old woman with a severe ovarian hyperstimulation syndrome (OHSS) as a complication of ovulation induction for primary infertility. The clinical picture showed massively enlarged ovaries, pleural effusion and haemoconcentration. She needed a thoracentesis for evacuation of the large pleural effusion. High levels of renin and prorenin were observed in plasma and pleural exudate. (C) 1997 Elsevier Science B.V.
\end{abstract}

Keywords: Ovarian hyperstimulation syndrome; Renin-angiotensin system; Pleural effusion; Thoracentesis

\section{Introduction}

The ovarian hyperstimulation syndrome (OHSS) is an iatrogenic complication of both ovulation induction and ovarian hyperstimulation affecting otherwise healthy young women. In its most pronounced form, the clinical picture of OHSS is dominated by massive enlargement of the ovaries, ascites, pleural effusion, oliguria, serum electrolyte disturbances and

\footnotetext{
* Corresponding author. Tel.: + 31104846611 ; fax: +31 10 4859959.

${ }^{1}$ Presented at: The 'Internistendagen', 25 and 26 April 1996, Veldhoven, the Netherlands (poster presentation). Published as abstract: van de Vrie, W, Baggen, MGA, Visser, W, Derkx, FHM, Ouwendijk, RJTh. High renin and aldosterone but normal prostaglandins in a patient with the ovarian hyperstimulation syndrome. Neth J Med 48:1996;A78, abstract 77.
}

hypercoagulability. The pathophysiological mechanisms underlying this syndrome are not fully known and no specific treatment is available [1-3]. We present here a patient with a severe form of OHSS and discuss the clinical picture, pathophysiology and treatment.

\section{Case report}

A 35-year-old woman who had a duodenal ulcer and sarcoidosis in her medical history, was bcing treated by the gynaecologist for primary infertility based on polycystic ovarian disease. She had not reacted to courses of clomiphene citrate. One month before admission she had started her first course of ovulation induction with human menopausal go- 
nadotropin (hMG) and human chorionic gonadotropin (hCG). She was treated with a step-up regime hMG (Pergonal, Serono, The Hague, The Netherlands) and needed a maximal dose of $150 \mathrm{IU}$ hMG a day for response. After 20 days, very large ovaries were seen by transvaginal ultrasound, with in both ovaries one follicle cyst of $19 \times 17 \mathrm{~mm}$ and many smaller follicular cysts. The possibility of the development of OHSS was discussed with the patient, after which it was decided to continue with ovulation induction. A single dose of $10000 \mathrm{IU}$ hCG (Pregnyl, Organon, Oss, the Netherlands) was given intramuscularly. Frequent out-paticnt visits wcre arranged, and bed rest at home was advised. After 5 days, she started to suffer from abdominal pain, which increased during the following days. Ten days after the hCG administration she was admitted to the hospital because of severe dyspnoea.

She complained of shortness of breath on minimal exercise and while lying horizontally, abdominal pain, and thirst. On physical examination she was tachypnoeic (frequency $40 / \mathrm{min}$ ). Her blood pressure was $110 / 65 \mathrm{mmHg}$, with a pulse rate of $88 / \mathrm{min}$. Examination of the heart was normal. Lung auscultation revealed diffusely spread rales and diminished breath sounds over the lower right hemithorax. Her abdomen was distended and tender on palpation. There were no clear signs of ascites, or of peripheral oedema. The haemoglobin level had increased over 10 days from 8.3 to $9.5 \mathrm{mmol} / \mathrm{l}$; the haematocrit had risen from 0.40 to $0.46 \%$; platelet count from 313000 to 424000 per $\mathrm{mm}^{3}$. The pregnancy test was positive and an ultrasonic examination later revealed a twin pregnancy. Various specific laboratory values were determined which are summarized in Table 1. Of note are a highly activated renin-angiotensin-aldosterone system, a normal angiotensin-converting enzyme (ACE) value, moderately elevated degradation products of prostaglandins and atrial natriuretic protein (ANP), and normal values for tumour necrosis factor- $\alpha$ (TNF- $\alpha$ ), the soluble TNF receptors, and arginine vasopressin (AVP). Chest X-ray showed a large pleural effusion in the right hemithorax and moderate pleural effusion in the left. There were no abnormalities indicating active sarcoidosis. Ultrasound of the abdomen showed a small quantity of peritoneal fluid around greatly enlarged ovaries (over $10 \mathrm{~cm}$ ) with rnultiple follicular cysts.
Table 1

Laboratory values of the patient with OHSS

\begin{tabular}{llll}
\hline Compounds $^{\text {a }}$ & Body fluid & Patient values & Normal values \\
\hline Progesterone & plasma & $980 \mathrm{nmol} / 1$ & $64-95 \mathrm{nmol} / 1^{\mathrm{b}}$ \\
& pleural exudate & $651 \mathrm{nmol} / 1$ & - \\
Renin (total) & plasma & $4447 \mu \mathrm{U} / \mathrm{ml}$ & $126-458 \mu \mathrm{U} / \mathrm{ml}$ \\
& pleural exudate & $5738 \mu \mathrm{U} / \mathrm{ml}$ & - \\
Prorenin & plasma & $3915 \mu \mathrm{m} / \mathrm{ml}$ & $112-407 \mu \mathrm{U} / \mathrm{ml}$ \\
& pleural exudate & $5103 \mu \mathrm{U} / \mathrm{ml}$ & - \\
Renin (active) & plasma & $514 \mu \mathrm{ml}$ & $14-51 \mu \mathrm{U} / \mathrm{ml}$ \\
& pleural exudate & $635 \mu \mathrm{ml}$ & - \\
Aldosterone & plasma & $1231 \mathrm{pg} / \mathrm{ml}$ & $<300 \mathrm{pg} / \mathrm{ml}$ \\
ACE & plasma & $8.6 \mathrm{mU} / \mathrm{ml}$ & $8-22 \mathrm{mU} / \mathrm{ml}$ \\
AVP & plasma & $0.6 \mathrm{pg} / \mathrm{ml}$ & $<10 \mathrm{pg} / \mathrm{ml}$ \\
ANP & plasma & $76 \mathrm{pg} / \mathrm{ml}$ & $20-50 \mathrm{pg} / \mathrm{ml}$ \\
TXB $_{2}$ & urine & $37 \mathrm{pg} / \mathrm{ml}$ & $<22 \mathrm{pg} / \mathrm{ml}$ \\
PGE $_{2}$ & urine & $50 \mathrm{pg} / \mathrm{ml}$ & $<22 \mathrm{pg} / \mathrm{ml}$ \\
PGF $_{1 \alpha}$ & urine & $19 \mathrm{pg} / \mathrm{ml}$ & $<17 \mathrm{pg} / \mathrm{ml}$ \\
Bio-TNF- $\alpha$ & plasma & $<6 \mathrm{pg} / \mathrm{ml}$ & $<6 \mathrm{pg} / \mathrm{ml}$ \\
sNFR $_{1}$ & plasma & $1.33 \mathrm{ng} / \mathrm{ml}$ & $1.08-2.03 \mathrm{ng} / \mathrm{ml}$ \\
sTNFR $_{2}$ & plasma & $5.78 \mathrm{ng} / \mathrm{ml}$ & $2.33-6.13 \mathrm{mg} / \mathrm{ml}$ \\
\hline
\end{tabular}

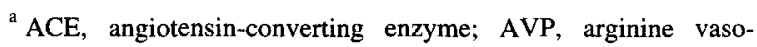
pressin; ANP, atrial natriuretic protein; $\mathrm{TXB}_{2}$, degradation product of trombexan $\left(\mathrm{TXA}_{2}\right) ; \mathrm{PGE}_{2}$, degradation product of prostaglandin; $\mathrm{PGF}_{1 \alpha}$, degradation product of prostacyclin $\left(\mathrm{PGI}_{2}\right)$; bioTNF- $\alpha$, bioactive tumour necrosis factor- $\alpha$; $\operatorname{sTNFR}_{1}$, soluble TNF receptor-1; sTNFR 2 , soluble TNF receptor-2.

${ }^{b}$ Reference values in first trimester of pregnancy.

${ }^{c}$ Detection level.

The patient was treated in the intensive care unit by a right-sided thoracentesis and 1.51 exudative fluid was evacuated. For intravascular volume depletion, she received intravenous saline fluid and diuresis could be maintained above a level of $30 \mathrm{ml} / \mathrm{h}$. To prevent thromboembolic complications, low-dose heparin was given intravenously. The remaining pleural effusion resolved spontaneously and no complications occurred. After 11 days, she was dismissed in clinically good health. The pregnancy did not last, however, and ended in a missed abortion.

\section{Discussion}

OHSS is a severe complication of ovulation induction. Its clinical spectrum varies from mild to life-threatening. Several deaths have been reported [1]. In mild forms, the ovaries are greatly enlarged causing abdominal distension and discomfort (grade 
1), that may be accompanied by nausea, vomiting and/or diarrhoea (grade 2). Moderate (grade 3) OHSS has the features of mild OHSS plus ultrasonic evidence of ascites. In severe OHSS (grade 4), there is also clinical evidence of ascites and/or hydrothorax or breathing difficulties. Grade 5 severe OHSS has all the described features plus changes in blood volume, increased blood viscosity due to haemoconcentration, coagulation abnormalities, and diminished renal perfusion and function [1]. In the most severe form, life-threatening complications are thromboembolic phenomena, renal failure, electrolyte disturbances, tense ascites and/or hydrothorax, and the adult respiratory distress syndrome [1,2]. The incidence of moderate and severe OHSS varies from 2 to $14 \%$; the incidence of severe OHSS is below $2 \%$ in most series [1,3-5]. Risk factors for developing severe OHSS are polycystic ovarian disease, conceptual cycles, possibly multiple gestation, and luteal phase supplementation with hCG. Ovulation induction with gonadotropin-releasing hormone agonists (GnRHa) and hMG confers a higher risk compared to stimulation with clomiphene citrate or hMG (without GnRHa). Women developing severe OHSS have higher serum levels of oestradiol and multiple immature and intermediate ovarian follicles [2-6]. Our patient had experienced no problems while using clomiphene citrate, but developed a severe (grade 5) OHSS after ovulation induction with hMG and hCG. She had multiple risk factors: polycystic ovarian disease; multiple small ovarian cysts after hMG administration; and a twin pregnancy. We realize that the decision to continue the treatment in our patient can be debated, taking into account all the many risk factors she had. For a woman who wants to become pregnant, it is difficult to decide on this matter as she may not oversee all possible consequences and risks of artificial ovarian stimulation. The development of OHSS can be prevented by discontinuation of the stimulation and withholding $\mathrm{hCG}$ administration. Ovulation will not then take place. Other measures have been proposed as well. It is advised to stop ovarian stimulation when serum oestradiol levels are high and many small follicles are seen by ultrasound $[1-3,5,7]$. Unfortunately, the oestradiol levels had not been measured in our patient.

The pathogenesis of OHSS is not clear. The tradi- tional hypothesis suggests an increase in vascular permeability, leading to leaking of intravascular fluid into third spaces and acute reduction of intravascular volume $[1,8]$. The distribution of extravascular fluid in OHSS suggests leakage from mesothelial membranes, which may be most susceptible to mediators of OHSS. Possible mediatory factors causing increased capillary permeability are prostaglandins, activated factors of the renin-angiotensin system, cytokines and various vasoactive factors [8-18],

It has been shown that an ovarian renin-angiotensin system is activated by gonadotrophins, resulting in high prorenin levels in preovulatory follicles [8]. Ovarian angiotensin II has an important role in oocyte maturation and ovulation [19]. In OHSS patients, extremely high levels of renin, prorenin, and immunoreactivity for angiotensin II have been found in plasma and ascites [9-13]. A direct correlation between plasma renin activity and severity of OHSS has been shown [9]. We show here that in the pleural effusion in a patient with OHSS, similar high levels of renin and prorenin are present. The elevated components of the renin-angiotensin system are most likely of ovarian origin $[10,11,13]$. Why prorenin, renin and angiotensin II are more elevated in ascites and pleural fluid than in plasma is not known. Direct ovarian-peritoneal transfer of luteal fluid might occur. Alternatively, changes in vascular or peritoneal permeability might change the influx-efflux equilibrium at the level of the mesothelium, leading to a rise in concentration of these components in the peritoneal and pleural cavity $[11,13]$. Angiotensin II might be the component that causes the increase in vascular permeability [8]. It is not known whether angiotensin II is activated by ACE, or whether an alternative pathway within the ovary could directly transform angiotensinogen into angiotensin II. The level of ACE in our patient was not elevated. An alternative pathway that activates angiotensin II would indicate that ACE inhibitors are not useful in the treatment of OHSS, but angiotensin II receptor blockers might prove beneficial in this syndrome [11].

Other possible mediators in OHSS are various components of the immune system that are known for their strong effects on vascular permeability. Cytokines, such as interleukin-2 (IL-2), IL-6, IL-8 and TNF, have been found elevated in OHSS [14- 
16]. In some studies, however, IL-2 and TNF levels were normal $[15,16]$. We also observed normal values for TNF- $\alpha$ and soluble TNF receptors in our patient. Recently, vascular endothelial growth factor (VEGF) has been proposed as a mediator in OHSS. VEGF was elevated in OHSS and blocking of the activity of VEGF by antiserum decreased capillary permeability in an animal model $[17,18]$.

An alternative hypothesis for the pathogenesis of OHSS has been proposed by Balasch et al., who showed that an early event in OHSS is intense peripheral arteriolar vasodilation $[20,21]$. The simultaneous occurrence of vascular underfilling by capillary leakage and the arteriolar vasodilation leads to a hyperdynamic circulation failure with compensatory activation of sympathetic nervous systems and the renin-angiotensin system to maintain blood pressure. Prostag]andins might be activated to antagonize the renal vasoconstrictor effects of the renin-angiotensin system. In our patient, we measured a slightly elevated urinary excretion of $\mathrm{TXB}_{2}, \mathrm{PGE}_{2}$, and $\mathrm{PGF}_{1 \alpha}$. Recently, endothelin, a potent naturally occurring vasoconstrictor compound, was found to be elevated in OHSS and the authors hypothesized a central role for this substance in the neurohormonal compensation for haemodynamic stress associated with OHSS [22].

Treatment of OHSS is based largely on empirical data. Mild OHSS requires no therapy apart from maintenance of oral hydration. Patients with moderate OHSS require close observation, preferably by hospitalisation, as rapid deterioration may occur, while severe OHSS urges immediate hospitalisation, eventually in an intensive care unit [2,3,7]. Haematocrit concentration should be followed as this correlates best with severity of OHSS [21,23]. Other parameters to be monitored are electrolyte status, liver and kidney function, and coagulation. Ultrasonography to assess ovarian size and intraperitoneal fluid volume should be done on admittance and during follow-up, when necessary [2,3,7]. Hypovolaemia is best treated by crystalloids $(\mathrm{NaCl})$ and human albumin $[2,3,7]$. The use of diuretics is highly controversial, but they may be used when haemodilution exists $[2,3,7,21]$. Ascites is best treated with paracentesis under ultrasonic guidance to prevent eventual puncture of an ovarian follicle [23,24]. Pleural effusion may diminish following abdominal paracentesis, but in the case of pleural effusion without ascites, thoracentesis immediately improves the dyspnoea and may reverse the clinical course $[25,26]$, as was also seen in our patient. Thromboembolic complications may be prevented by prophylactic use of heparin. In the most severe form, OHSS is complicated by multiple organ failure, which requires specific treatment in the intensive care unit $[2,3]$. There is no place for treatment with nonsteroidal anti-inflammatory drugs or angiotensinconverting enzyme inhibitors, because, as described above, they have no proven effect in studies and they may block beneficial counteracting mechanisms in OHSS $[1,2,21]$.

\section{Acknowledgements}

The authors would like to thank Prof. Dr. F.H. de Jong for determination of progesterone, Dr. I. Beckman for determination of bioactive TNF- $\alpha$ and its soluble receptors, and Dr. F.J. Zijlstra for measurement of the urinary eicosanoids.

\section{References}

[1] Golan A, Ron-El R, Herman A, Soffer Y, Weinraub Z, Caspi E. Ovarian hyperstimulation syndrome: an update review. Obstet Gynecol Surv 1989:44:430-440.

[2] Navot D, Bergh PA, Laufer N. Ovarian hyperstimulation syndrome in novel reproductive technologies: prevention and treatment. Fertil Steril 1992;58:249 261.

[3] Brinsden PR, Wada I, Tan SL, Balen A, Jacobs HS. Diagnosis, prevention and management of ovarian hyperstimulation syndrome. Br J Obstet Gynaecol 1995;102:767-772.

[4] Smitz J, Camus M, Devroey P, Erard P, Wisanto A, Van Steirteghem AC. Incidence of severe ovarian hyperstimulation syndrome after GnRH agonist/HMG superovulation for in-vitro fertilization. Hum Reprod 1990;5:933-937.

[5] Rizk B, Smitz J. Ovarian hyperstimulation syndrome after superovulation using GnRH agonists for IVF and related procedures. Hum Reprod 1992;7:320-327.

[6] Delvigne A, Demoulin A, Smitz J, et al. The ovarian hyperstimulation syndrome in in-vitro fertilization: a Belgian multicentric study

I. Clinical and biological features. Hum Reprod 1993;8:1353-1360.

[7] Schenker JG. Prevention and treatment of ovarian hyperstimulation. Hum Reprod 1993;8:653-659.

[8] Bergh PA, Navot D. Ovarian hyperstimulation syndrome: a review of pathophysiology. J Assist Reprod Genet 1992;9:429-438. 
[9] Navot D, Margalioth EJ, Laufer N, et al. Direct correlation between plasma renin activity and severity of the ovarian hyperstimulation syndrome. Fertil Steril 1987;48:57-61.

[10] Ong ACM, Elsen V, Rennie DP, et al. The pathogenesis of the ovarian hyperstimulation syndrome (OHS): a possible role for ovarian renin. Clin Endocrinol 1991;34:43-49.

[11] Delbaere A, Rergmann PJM, Gervy-Decoster C, Staroukine $\mathrm{M}$, Englert $\mathrm{Y}$. Angiotensin II immunoreactivity is elevated in ascites during severe ovarian hyperstimulation syndrome: implications for pathophysiology and clinical management. Fertil Steril 1994;62:731-737.

[12] Rosenberg ME, Mckenzie JK, Mckenzie IM, Junaid A, Tagatz $\mathrm{GE}$. Increased ascitic fluid prorenin in the ovarian hyperstimulation syndrome. Am J Kidney Dis 1994;23:427-429.

[13] Itskovitz-Eldor J, Kol S, Lewit N, Sealey JE. Ovarian origin of plasma and peritoneal fluid prorenin in early pregnancy and in patients with ovarian hyperstimulation syndrome. $J$ Clin Endocrinol Metab 1997:82:461-464.

[14] Friedlander MA, Loret de Mola JR, Goldfarb JM. Elevated levels of interleukin- 6 in ascites and serum from women with ovarian hyperstimulation syndrome. Fertil Steril 1993;60:826-833.

[15] Orvieto R, Voliovitch I, Fishman P, Ben-Rafael Z. Interleukin-2 and ovarian hyperstimulation syndrome: a pilot study. Hum Reprod 1995;10:24-27.

[16] Revel A, Barak V, Lavy Y, et al. Characterization of intraperitoneal cytokines and nitrites in women with severe ovarian hyperstimulation syndrome. Fertil Steril 1996;66:66-71.

[17] McClure N, Healy DL, Rogers PAW, et al. Vascular endothelial growth factor as capillary permeability agent in ovarian hyperstimulation syndrome. Lancet 1994;344:235236 .
[18] Abramov Y, Barak V, Nisman B, Schenker JG. Vascular endothelial growth factor plasma levels correlate to the clinical picture in severe ovarian hyperstimulation syndrome. Fertil Steril 1997;67:261-265.

[19] Morris RS, Paulson RJ. Ovarian derived prorenin-angiotensin cascade in human reproduction. Fertil Steril 1994;62:1105-1114.

[20] Balasch J, Arroyo V, Carmona F, et al. Severe ovarian hyperstimulation syndrome: role of peripheral vasodilation. Fertil Stcril 1991;56:1077-1083.

[21] Balasch J, Arroyo V, Fábregues F, et al. Neurohormonal and hemodynamic changes in severe cases of the ovarian hyperstimulation syndrome. Ann Intern Med 1994;121:27-33.

[22] Balasch J, Arroyo V, Fábregues F, Jiménez W, Saló J, Vanrell JA. Immunoreactive endothelin plasma levels in severe ovarian hyperstimulation syndrome. Fertil Steril 1995;64:65-68.

[23] Borenstein R. Elhalah U, Lunenfeld B. Shoham Schwartz Z. Severe ovarian hyperstimulation syndrome: a reevaluated therapeutic approach. Fertil Steril 1989;51:791-795.

[24] Padilla SL, Zamaria S, Baramki TA, Garcia JE. Abdominal paracentesis for the ovarian hyperstimulation syndrome with severe pulmonary compromise. Fertil Steril 1990;53:365367.

[25] Hsieh MJ, Tsao TC, Cheng PJ. Ovarian hyperstimulation syndrome with minimal ascites and massive pleural effusion: report of a case. J Formos Med Assoc 1994;93:882-884.

[26] Rinaldi ML, Spirtos NJ. Chest tube drainage of pleural effusion correcting abdominal ascites in a patient with severe ovarian hyperstimulation syndrome: a case report. Fertil Steril 1995;63:1114-1117. 